\title{
Influences of $\beta$-Mercaptoethylamine and Oxygen Removal on the X-ray Sensitivity of Four Strains of Escherichia coli
}

\author{
BY H. L. CROMROY AND H. I. ADLER \\ Biology Division, Oak Ridge National Laboratory, Oak Ridge, Tennessee, U.S.A.
}

(Received 26 August 1961)

SUMMARY

In four strains of Escherichia coli B/r (ORNL), B (ORNL), B (Hill), Bs (Hill) protection by $\beta$-mercaptoethylamine (MEA) exceeded that observed for oxygen removal by nitrogen bubbling. Although only a slight decrease of protection was found with strain Bs (Hill) when oxygen was removed by nitrogen bubbling, the protection afforded by MEA in excess of that achieved by nitrogen bubbling was similar with all four strains. The data suggest that at least two mechanisms for protection by MEA may operate simultaneously in some bacteria and that one of these is a removal of oxygen equivalent to that achieved by nitrogen gas bubbling.

\section{INTRODUCTION}

Hollaender \& Doudney (1954) and Elias (1961) showed that $\beta$-mercaptoethylamine (MEA) provided protection from X-rays in Escherichia coli $\mathrm{B} / \mathbf{r}$ (ORNL) greater than that achieved by removal of oxygen by nitrogen gas bubbling. Other workers, with different techniques and possibly different strains, reported much lower protection with MEA (Marcovich, 1957). The present work was done with four strains of $\boldsymbol{E}$. coli under standardized experimental conditions to determine whether MEA protected all strains to the same degree and to compare the effect of oxygen removal on these strains. We anticipated that if differences were found, these might be used in a study of MEA action. Such differences have been found and two mechanisms of action are proposed.

\section{MATERIALS}

The four strains used were Escherichia coli strains B/r (ORNL), B (ORNL), B (Hill), and Bs (Hill). Strains B/r (ORNL) and B (ORNL) were obtained originally from Dr Evelyn Witkin and were recently recharacterized by Adler \& Haskins (1960). Strains B (Hill) and Bs (Hill) were provided by Dr Ruth Hill. Strain Bs (Hill) has been reported as very sensitive to both ultraviolet (Hill, 1958; Hill \& Simson, 1961) and X irradiation (Hill \& Simson, 1961; Engel \& Adler, 1961).

The organisms were grown and $\mathrm{X}$-irradiated by the technique described by Elias (1961). The bacteria were plated on Difco nutrient agar.

The refined nitrogen-gas technique used was similar to that of Birge \& Tobias (1954). It consisted of passing tank nitrogen (High Purity dry, 99.98\%) over copper turnings in a quartz tube heated to $750^{\circ}$. The gas was then bubbled through a sterile water wash three alkaline pyrogallol solutions $[600 \mathrm{~g} . \mathrm{KOH}+300 \mathrm{~g}$. pyrogallic acid per 1.], two additional water washes, and conducted to irradiation tubes. 
Nitrogen gas was passed through the system for $15 \mathrm{~min}$. before attaching the irradiation bubbling tubes; then suspensions were bubbled for $15 \mathrm{~min}$. before irradiation and continuously during irradiation. No quantitative measurements were made of the purity of the nitrogen. Although the oxygen used was not purified, the bubbling treatment was similar to the nitrogen bubbling.

MEA was added to suspensions of organisms $30 \mathrm{~min}$. before irradiation; incubation was at $0-1^{\circ}$ in closed vials. Incubation was maintained at $0-1^{\circ}$ until the irradiation was completed. At concentrations of MEA up to and including 0.12 $\mathrm{M}$, no lethal effect was observed in the controls.

In experiments in which the protective effect of sodium dithionite $\left(\mathrm{Na}_{2} \mathrm{~S}_{2} \mathrm{O}_{4}\right)$ was measured, the salt was present at a final concentration of $0.02 \mathrm{M}$, which provided maximum protection, according to Stapleton (1960). Samples were prepared by adding bacterial suspensions in saline solution directly to the dry sample of $\mathrm{Na}_{2} \mathrm{~S}_{2} \mathrm{O}_{4}$ immediately before irradiation.

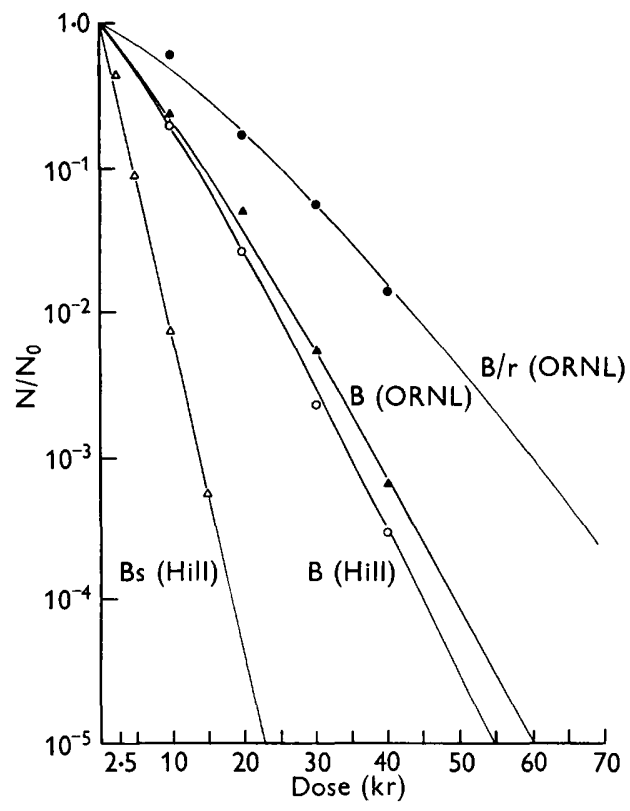

Fig. 1

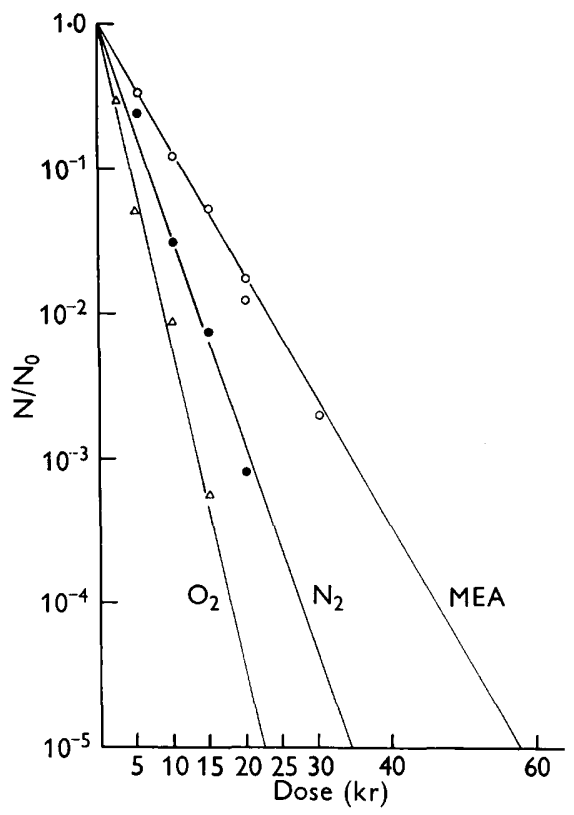

Fig. 2

Fig. 1. X-ray survival curves for four strains of Escherichia coli in a suspending medium of $8.5 \mathrm{~g}$. $\mathrm{NaCl} / \mathrm{l}$. and bubbled with oxygen during irradiation. The points represent averages of three or more experiments.

Fig. 2. X-ray survival curves for Escherichia coli strain Bs (Hill) in oxygen, in nitrogen, and in $0.06 \mathrm{M}$-MEA ( $\beta$-mercaptoethylamine). The suspending medium was $8.5 \mathrm{~g} . \mathrm{NaCl} / \mathrm{l}$. The points represent the average of three or more separate experiments.

\section{RESULTS AND DISCUSSION}

The differences in sensitivity of the Escherichia coli strains used to ionizing radiation in the absence of protective agent are shown in Fig. 1. We confirmed the results of Elias (1961) with $E$. coli B/r (ORNL). 
When we compared survival curves for MEA-treated organisms and those irradiated in oxygen (MEA/O $\mathrm{O}_{2}$ ), a DRF of approximately 6 was obtained whereas a dose reduction factor (DRF) of 3 was observed as between oxygenated suspensions and those made anoxic by nitrogen bubbling $\left(\mathrm{N}_{2} / \mathrm{O}_{2}\right)$. The use of DRF (dose reduction factor defined by Alexander (1960) as the radiation dose which produces a given effect in the presence of protector divided by the radiation dose which produces a given effect without protector) to indicate relative sensitivity of cells in oxygen and MEA was appropriate since these curves, in agreement with the results of Elias (1961), seemed to be multiples of each other. In earlier work (Hollaender \& Doudney, 1954), survival curves for cells in MEA were clearly not multiples of those for cells in oxygen. We are not able to account for this discrepancy.

The experiments done with strain Bs (Hill) using the same technique are shown in Fig. 2; the DRF for $\mathrm{MEA} / \mathrm{O}_{2}$ was about $2 \cdot 6$. The small magnitude of chemical protection observed with this strain indicated the possibility that the amount of MEA (0.06 M) used was not optimum. Experiments on the concentration of MEA against survival to $20 \mathrm{kr}$ of X irradiation (Fig. 3) showed that protection was not much increased beyond $0.06 \mathrm{M}$ MEA. These experiments also verified that MEA was not toxic to the cells up to $0 \cdot 12 \mathrm{M}$ over the time period required for the experiments.

In another attempt to explain the small MEA effect in strain Bs (Hill), we examined the protection achieved by oxygen removal with nitrogen bubbling in this strain. It can be seen (Fig. 2) that the oxygen effect in this radiation-sensitive organism was considerably smaller than that obtained for Escherichia coli $\mathrm{B} / \mathrm{r}$ (ORNL) by Elias (1961).

We examined the magnitude of the oxygen effect for two ' $B$ ' strains and found it to be intermediate between that for strains Bs (Hill) and $B / r$ (ORNL). It can be seen (Table 1) that in this group of bacteria there was a correlation between radiation resistance, magnitude of the oxygen effect and magnitude of the MEA effect.

Table 1. Oxygen and $M E A$ effects on strains of Escherichia coli

\begin{tabular}{|c|c|c|c|}
\hline & $\frac{\mathrm{N}_{2}}{\mathrm{O}_{2}}$ & $\frac{\text { MEA } \dagger}{\mathrm{O}_{2}}$ & $\begin{array}{r}\text { LD50 } \\
(\mathbf{K r})\end{array}$ \\
\hline Strain of $E$. coli & \multicolumn{2}{|c|}{ DRF* value } & \\
\hline B/r (ORNL) & $3 \cdot 2$ & $6 \cdot 0$ & $14 \cdot 0$ \\
\hline B (ORNL) & $2 \cdot 4$ & $\mathbf{3 \cdot 9}$ & $7 \cdot 0$ \\
\hline B (Hill) & $\mathbf{2 \cdot 2}$ & $\mathbf{3} \cdot \mathbf{3}$ & $6 \cdot 2$ \\
\hline Bs (Hill) & $1 \cdot 5$ & $2 \cdot 6$ & $\mathbf{2 \cdot 2}$ \\
\hline
\end{tabular}

* DRF is average figure for five determinations.

$\dagger$ MEA $=\beta$-mercaptoethylamine.

Attempts to enhance the oxygen effect in strain Bs (Hill) by further purification of the nitrogen resulted in only a small increase in the value of $\mathrm{DRF} \mathrm{N}_{2} / \mathrm{O}_{2}$ from about 1.4 to 1.7 . Although the reason for the small oxygen effect is not at present understood, the fact that it exists does aid in understanding the small $\mathrm{MEA} / \mathrm{O}_{2}$ DRF value observed for this organism. These observations also are consistent with the hypothesis that MEA protects in at least two ways. One offers protection equivalent to that obtained by nitrogen bubbling. Above this a second increment of protection was observed. This increment was about the same for both the Bs and $\mathrm{B} / \mathrm{r}$ strains; the $\mathrm{DRF}$ value for $\mathrm{MEA} / \mathrm{N}_{2}$ was about 1.7 . Thus, it is only the first 
increment, obtainable with either nitrogen bubbling or low concentrations of MEA, that is small in the Bs (Hill) strain. Further support for the concept that MEA can protect by two mechanisms is presented in Fig. 4. Here relative radiosensitivity is plotted as a function of MEA concentration. If MEA operates solely as an agent to remove oxygen, this plot should be equivalent to that of Howard-Flanders \& Alper (1957) in which relative radiosensitivity was plotted as a function of oxygen concentration. Indeed, over the range from about zero concentration to $0.012 \mathrm{M}$ MEA, this curve, being a linear function of MEA concentration, is equivalent. At higher concentrations of MEA, however, the slope changed and no longer resembled that of the earlier data. This inflexion occurred at a relative radiosensitivity of 1 , obtainable either by exhaustive nitrogen bubbling or with 0.012 M MEA under our conditions. The fact that the slope is different in the concentration range of $0.012 \mathrm{M}$ to $0.12 \mathrm{M}$ MEA supports the contention that a second mechanism is involved.

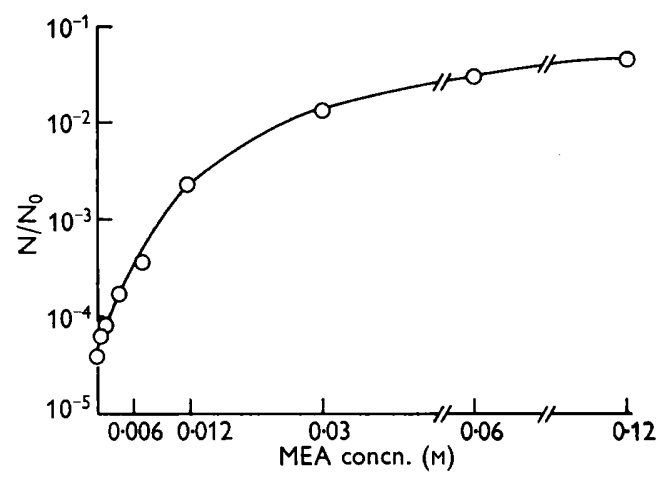

Fig. 3

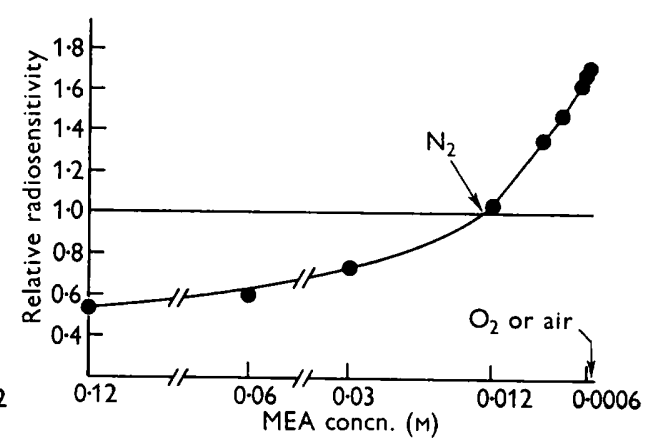

Fig. 4

Fig. 3. Surviving fraction of Escherichia coli strain Bs (Hill) to $20 \mathrm{kr}$ as a function of MEA ( $\beta$-mercaptoethylamine) concentration. The suspending medium was $8.5 \mathrm{~g} . \mathrm{NaCl} / \mathrm{l}$. The points represent an average of five separate experiments.

Fig. 4. Relative radiosensitivity (Howard-Flanders \& Alper, 1957) of Escherichia coli strain Bs (Hill) as a function of MEA ( $\beta$-mercaptoethylamine) concentration.

This second mechanism might involve oxygen; if this be so, the oxygen must be bound to the cells in a manner not susceptible to removal by nitrogen bubbling. With this in mind, were made experiments in which $\mathrm{Na}_{2} \mathrm{~S}_{2} \mathrm{O}_{4}$ was used as the oxygenremoving agent. This compound is an excellent oxygen 'getter' and protects Escherichia coli strain $\mathrm{B} / \mathrm{r}$ slightly better than oxygen removal by nitrogen bubbling. When $\mathrm{Na}_{2} \mathrm{~S}_{2} \mathrm{O}_{4}$ was used with $E$. coli strain $\mathrm{Bs}$, the protection observed was as good as that achieved by nitrogen bubbling. However, the magnitude of the protective effect is limited by the toxicity of $\mathrm{Na}_{2} \mathrm{~S}_{2} \mathrm{O}_{4}$ for this strain. The indication is that an efficient chemical oxygen 'getter' does not duplicate the action of MEA.

The data presented here and elsewhere (Bacq \& Alexander, 1961; Graevskii \& Konstantinova, 1961) indicate that MEA can bring about protection by at least two mechanisms. One of these may be oxygen removal, and a complete understanding of this depends on an understanding of the oxygen effect. By using the Bs (Hill) strain of Escherichia coli in which the protective effect produced by oxygen removal is minimized, and the $\mathrm{B} / \mathrm{r}$ strain, in which it is large, we hope to characterize the second mechanism. 
One of the authors (H.L.C.) was a Research Participant at Oak Ridge National Laboratory operated by Union Carbide Corporation for the U.S Atomic Energy Commission.

\section{REFERENCES}

Adler, H. I. \& Haskins, S. D. (1960). Heterogeneity of cultures of Escherichia coli B/r. Nature, Lond. 188, 249.

Alexander, P. (1960). Protection of macromolecules in vitro against damage by ionizing radiation. In: Radiation Protection and Recovery, p. 3. Ed. A. Hollaender. New York: Pergamon Press.

BacQ, Z. M. \& Alexander, P. (1961). Fundamentals of Radiobiology, second edition, p. 470. New York: Pergamon Press.

Birge, A. C. \& Tobias, C. A. (1954). Radiation sensitivity of yeast cells grown in aerobic and anaerobic environments. Arch. Biochem. Biophys. 52, 388.

Elias, C. A. (1961). The x-ray sensitivity of Escherichia coli in the presence of $\beta$-mercaptoethylamine. Radiat. Res. 15, 632.

EnGEL, M. S. \& AdLer, H. I. (1961). Catalase activity, sensitivity to hydrogen peroxide, and radiation response in the genus Escherichia. Radiat. Res. 15, 269.

Graevskit, E. Ya. \& Konstantinova, M. M. (1961). Investigation of the mechanism of the antiradiation protective effect of certain sulphur-containing substances. Proc. Acad. Sci. (U.S.S.R.) Biol. Sci. Sect. (English translation), 133, 506.

HiLl, R. F. (1958). A radiation-sensitive mutant of Escherichia coli. Biochim. biophys. Acta, 30, 636.

Hill, R. F. \& Simson, E. (1961). A study of radiosensitive and radioresistant mutants of Escherichia coli strain B. J. gen. Microbiol. 24, 1.

Hollaender, A. \& Doudney, C. O. (1954). Studies on the mechanisms of radiation protection and recovery with cysteamine and $\beta$-mercaptoethanol. In: Radiobiology Symposium, p. 112. Ed. by Z. M. Bacq and P. Alexander. London: Butterworths Scientific Publications.

Howard-Flanders, P. \& Alper, T. (1957). The sensitivity of microorganisms to irradiation under controlled gas conditions. Radiat. Res. $7,518$.

Marcovich, H. (1957). Sur le mechanisme de l'activité radioprotectrice de la cystéamine chez les bactéries. Ann. Inst. Pasteur, 93, 456.

Stapleton, G. E. (1960). Protection and recovery in bacteria and fungi. In: Radiation Protection and Recovery, p. 99. Ed. A. Hollaender. New York: Pergamon Press. 